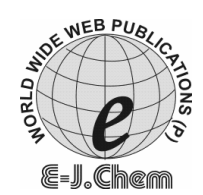

http://www.e-journals.net

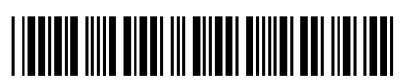

ISSN: 0973-4945; CODEN ECJHAO E-Journal of Chemistry 2008, 5(S1), 1033-1036

\title{
Studies on Synthesis and Dyeing Preformance of Acid Dyes Based on 4,7-Dihydroxy-1,10-Phenanthroline-2,9-Dione
}

\author{
B. V. PATEL ${ }^{*}$ and P. H. DASONDI \\ Chemistry Department, \\ Sir P. T. Sarvajanik College of Science, Surat-395 001. India. \\ dr.bhupesh1960@yahoo.co.in
}

Received 17 October 2007; Accepted 10 December 2007

\begin{abstract}
Some new azo acid dyes were prepared by coupling various diazotized acid components such as anthranilic acid, sulphanilic acid, laurent acid, peri acid, tobias acid, H-acid, J-acid, gamma acid, sulphotobias acid, 4-aminotoluiene-3sulphonic acid, 5-sulpho- anthranilic acid, 2-naphthylamine-3,6,8-trisulphonic acid, bronner acid, metanilic acid and cleve acid with 4,7-dihydroxy-1,10phenanthroline-2,9-dione. The dyes were characterized by elemental, IR and TLC analyses. Their dyeing performance as acid dyes has been assessed on viscose rayon, wool and cotton fibres.
\end{abstract}

Keywords: Acid azo dyes, Dyeing performance, IR.

\section{Introduction}

The newest additions of existing acid dyes are the centre of attraction in dyestuff research ${ }^{1}$. Various dyes based on quinazoline, quinoline and 4-oxo-quinazoline ring system have been reported to be useful on natural and man-made fibres, showed high affinity and good dyeing performance ${ }^{2-4}$. Some of them also showed potential biological activity. Therefore it was thought interesting to study the synthesis, characterization and dyeing performance of various acid dyes based on 4,7-dihydroxy-1,10-phenanthroline-2,9dione heterocyclic ring system.

\section{Experimental}

Melting points were determined in open capillaries and are uncorrected. The IR spectra $(\mathrm{KBr})$ were recorded on a Perkin-Elmer spectrophotometer (Model 377). UV-Visible spectra were recorded on Backman DB-GT grating spectrophotometer using $1 \times 10^{-3} \mathrm{M}$ aqueous solution. TLC was carried out on Silica gel-G as absorbent using reported procedure ${ }^{5}$. 
Synthesis of 4,7-dihydroxy-1,10-phenanthroline-2,9-dione (A)

A solution of $o$-phenylenediamine $(0.1$ mole, $10.80 \mathrm{~g})$ in diethyl malonate $(0.22$ mole, $13.930 \mathrm{~mL}$ ) was added portion wise to poly phosphoric acid (prepared from $38.6 \mathrm{~g} \mathrm{P}_{2} \mathrm{O}_{5}$ and $21.4 \mathrm{~mL}$ of orthophosphoric acid). The deep green pasty mass obtained was heated at $170^{\circ} \mathrm{C}$ for 30 minutes. The reaction mixture was left to cool and poured into cold water. The solution obtained was neutralized with $5 \% \mathrm{NaOH}$ solution. The product obtained was filtered, dried and crystallized. m.p. $315^{\circ} \mathrm{C}$, yield $75 \%$.

\section{Coupling of diazotized acid component with (A)}

The coupling component ( 0.01 mole, $5.32 \mathrm{~g}$.) was suspended in $\mathrm{NaOH}(10 \%, 15 \mathrm{~mL})$ and the $\mathrm{pH}$ of the solution is maintained neutral with sodium carbonate solution $(10 \% \mathrm{w} / \mathrm{v})$ to obtain a clear solution. The solution was cooled to $0-5^{\circ} \mathrm{C}$ and the cooled diazo solution of acid component ( 0.01 mole) was added drop wise with stirring, maintaining the $\mathrm{pH}$ to 8.0 by simultaneous addition of sodium carbonate $(10 \% \mathrm{w} / \mathrm{v})$. Stirring was continued for 2 hours at $0-5^{\circ} \mathrm{C}$. The reaction mixture was heated to $60^{\circ} \mathrm{C}$ after $2 \mathrm{~h}$ and sodium chloride was added till the dyestuff is precipitated out. After stirring for an hour the liquor was filtered and the product was washed with a small amount of 5\% sodium chloride solution. The dye was dried at $90^{\circ} \mathrm{C}$. It was then purified by extraction with DMF and precipitation by diluting the DMF extract with acetone.

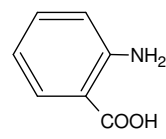

1 mole
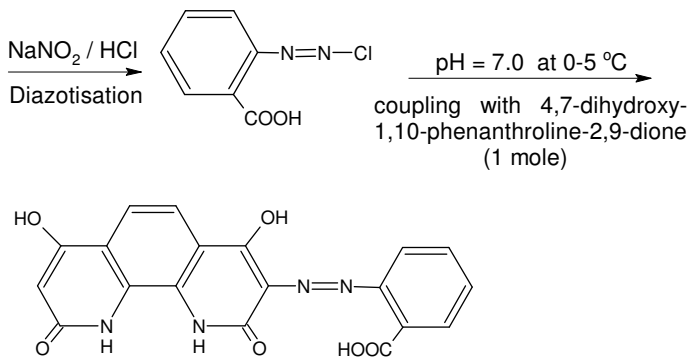

$\left(\mathrm{D}_{1}\right)$

\section{Dyeing of fibres}

Reaction Scheme

All the dyes $D_{1}$ to $D_{15}$ were applied on viscose rayon, wool and cotton fibres in $2 \%$ shade by using the reported procedure ${ }^{6}$.

\section{Fastness test}

Fastness to the light was assessed in accordance with BS:1006-1978 and the wash fastness was assessed in accordance with IS:765-1979.

\section{Results and Discussion}

The melting point, $\%$ yield, $\% \mathrm{~N}, \mathrm{R}_{\mathrm{f}}$ values and $\lambda_{\max }$ values of the dyes synthesized are given in Table 1. All the dyes were obtained in excellent yield (68-81\%). TLC of the samples indicates single spot purity for all the dyes. The IR spectra of the dyes $D_{1}$ to $D_{15}$ showed characteristic band at 3000-3235 $\mathrm{cm}^{-1}(-\mathrm{OH}), 3330-3455 \mathrm{~cm}^{-1}(-\mathrm{NH}), 1590-1640 \mathrm{~cm}^{-1}$ $(-\mathrm{C}=\mathrm{O}), 1380-1450$ and $170 \mathrm{~cm}^{-1}(-\mathrm{N}=\mathrm{N}-), 1050-1250 \mathrm{~cm}^{-1}\left(-\mathrm{SO}_{3} \mathrm{H}\right)$.

All the dyes $D_{1}$ to $D_{15}$ were applied to viscose rayon, wool and cotton fibres gave violet, blue, green, yellow, orange brown and maroon shades. $\mathrm{D}_{7}, \mathrm{D}_{8}, \mathrm{D}_{11}, \mathrm{D}_{14}, \mathrm{D}_{15}$ gives deeper shades on all three fibres. Most of the dyes give green shades. The $\%$ exhaustion and 
fastness data of dyes $D_{1}$ to $D_{15}$ are given in Table 2 indicates good affinity for all the fibres used in study. The pick-up values of these dyes varied from 2 to 4 . The light fastness varied from poor to fairly good whereas fastness to washing varied from fair to excellent. Exhaustion ranges from $63.75 \%$ to $74.50 \%$.

Table 1. Physical data for acid dyes

\begin{tabular}{lllcrcrc}
\hline $\begin{array}{l}\text { Dye } \\
\text { No. }\end{array}$ & \multicolumn{1}{c}{ Diazo component (R) } & \multicolumn{1}{c}{$\begin{array}{c}\text { Molecular } \\
\text { formula }\end{array}$} & $\begin{array}{c}\% \mathrm{~N} \\
\text { found }\end{array}$ & $\begin{array}{c}\text { m.p. } \\
{ }^{\circ} \mathrm{C}\end{array}$ & $\begin{array}{c}\% \\
\text { yield }\end{array}$ & $\lambda_{\max }$ & $\mathrm{R}_{\mathrm{f}}$ \\
\hline $\mathrm{D}_{1}$ & Anthranilic acid & $\mathrm{C}_{19} \mathrm{H}_{12} \mathrm{~N}_{4} \mathrm{O}_{6}$ & 15.60 & 170 & 79 & 226 & 0.91 \\
$\mathrm{D}_{2}$ & Sulphanilic acid & $\mathrm{C}_{18} \mathrm{H}_{11} \mathrm{~N}_{4} \mathrm{O}_{7} \mathrm{SNa}$ & 12.50 & 155 & 72 & 301 & 0.89 \\
$\mathrm{D}_{3}$ & Laurent acid & $\mathrm{C}_{22} \mathrm{H}_{11} \mathrm{~N}_{4} \mathrm{O}_{7} \mathrm{SNa}$ & 11.24 & 165 & 80 & 306 & 0.83 \\
$\mathrm{D}_{4}$ & Peri acid & $\mathrm{C}_{22} \mathrm{H}_{11} \mathrm{~N}_{4} \mathrm{O}_{7} \mathrm{SNa}$ & 11.25 & 190 & 77 & 389 & 0.79 \\
$\mathrm{D}_{5}$ & Tobias acid & $\mathrm{C}_{22} \mathrm{H}_{11} \mathrm{~N}_{4} \mathrm{O}_{7} \mathrm{SNa}$ & 11.28 & 180 & 75 & 319 & 0.81 \\
$\mathrm{D}_{6}$ & H-acid & $\mathrm{C}_{22} \mathrm{H}_{12} \mathrm{~N}_{4} \mathrm{O}_{11} \mathrm{~S}_{2} \mathrm{Na}_{2}$ & 9.10 & 120 & 65 & 560 & 0.83 \\
$\mathrm{D}_{7}$ & J-acid & $\mathrm{C}_{22} \mathrm{H}_{13} \mathrm{~N}_{4} \mathrm{O}_{8} \mathrm{SNa}$ & 10.89 & 160 & 69 & 410 & 0.78 \\
$\mathrm{D}_{8}$ & Gamma acid & $\mathrm{C}_{22} \mathrm{H}_{13} \mathrm{~N}_{4} \mathrm{O}_{8} \mathrm{SNa}$ & 10.88 & 190 & 71 & 252 & 0.91 \\
$\mathrm{D}_{9}$ & Sulphotobias acid & $\mathrm{C}_{22} \mathrm{H}_{12} \mathrm{~N}_{4} \mathrm{O}_{10} \mathrm{~S}_{2} \mathrm{Na}_{2}$ & 9.34 & 170 & 74 & 398 & 0.91 \\
$\mathrm{D}_{10}$ & 4-aminotoluene-3- & $\mathrm{C}_{19} \mathrm{H}_{13} \mathrm{~N}_{4} \mathrm{O}_{7} \mathrm{SNa}$ & 12.10 & 199 & 78 & 398 & 0.89 \\
& sulphonic acid & & & & & & \\
$\mathrm{D}_{11}$ & 5-sulpho anthranilic acid & $\mathrm{C}_{19} \mathrm{H}_{11} \mathrm{~N}_{4} \mathrm{O}_{9} \mathrm{SNa}$ & 11.25 & 135 & 72 & 240 & 0.91 \\
$\mathrm{D}_{12}$ & 2-naphthylamine-3,6,8- & $\mathrm{C}_{22} \mathrm{H}_{11} \mathrm{~N}_{4} \mathrm{O}_{13} \mathrm{~S}_{3} \mathrm{Na} 3$ & 7.99 & 230 & 80 & 330 & 0.88 \\
& trisulphonic acid & & & & & & \\
$\mathrm{D}_{13}$ & Bronner acid & $\mathrm{C}_{22} \mathrm{H}_{13} \mathrm{~N}_{4} \mathrm{O}_{7} \mathrm{SNa}$ & 11.28 & 160 & 79 & 325 & 0.84 \\
$\mathrm{D}_{14}$ & Metanilic acid & $\mathrm{C}_{18} \mathrm{H}_{11} \mathrm{~N}_{4} \mathrm{O}_{7} \mathrm{SNa}$ & 12.50 & 170 & 75 & 320 & 0.81 \\
$\mathrm{D}_{15}$ & Cleve acid & $\mathrm{C}_{22} \mathrm{H}_{13} \mathrm{~N}_{4} \mathrm{O}_{7} \mathrm{SNa}$ & 11.25 & 120 & 81 & 410 & 0.79 \\
\hline
\end{tabular}

Table 2. \% Exhaustion, Light fastness and Wash fastness data

\begin{tabular}{cccccccccc}
\hline Dye & \multicolumn{3}{c}{ Viscos rayon } & \multicolumn{3}{c}{ Wool } & \multicolumn{3}{c}{ Cotton } \\
\cline { 2 - 11 } No. & $\%$ Ex. & L.F. & W.F. & $\%$ Ex. & L.F. & W.F. & $\%$ Ex. & L.F. & W.F. \\
\hline $\mathrm{D}_{1}$ & 63.75 & $4-5$ & $2-3$ & 66.25 & $4-5$ & 3 & 66.25 & 4 & $4-5$ \\
$\mathrm{D}_{2}$ & 66.25 & 4 & $3-4$ & 67.50 & $3-4$ & 3 & 63.75 & $3-4$ & 4 \\
$\mathrm{D}_{3}$ & 65.00 & $3-4$ & $2-3$ & 70.00 & $2-3$ & $4-5$ & 54.45 & $2-3$ & $3-4$ \\
$\mathrm{D}_{4}$ & 72.00 & $3-4$ & 3 & 73.75 & 3 & $3-4$ & 71.25 & $4-5$ & 3 \\
$\mathrm{D}_{5}$ & 68.00 & $2-3$ & 3 & 70.50 & $4-5$ & $2-3$ & 71.75 & $4-5$ & $4-5$ \\
$\mathrm{D}_{6}$ & 70.00 & 3 & 3 & 67.50 & 4 & 3 & 74.50 & 4 & $2-3$ \\
$\mathrm{D}_{7}$ & 65.50 & 3 & $3-4$ & 70.00 & $2-3$ & $4-5$ & 73.00 & $3-4$ & 3 \\
$\mathrm{D}_{8}$ & 67.00 & 3 & $3-4$ & 66.75 & 3 & 4 & 70.00 & $2-3$ & 4 \\
$\mathrm{D}_{9}$ & 68.75 & $3-4$ & $2-3$ & 63.75 & 4 & 4 & 68.75 & 3 & $3-4$ \\
$\mathrm{D}_{10}$ & 70.50 & $2-3$ & 3 & 64.45 & $3-4$ & $3-4$ & 67.50 & 4 & 4 \\
$\mathrm{D}_{11}$ & 73.75 & $3-4$ & 3 & 71.25 & 3 & $2-3$ & 67.00 & $4-5$ & $2-3$ \\
$\mathrm{D}_{12}$ & 74.50 & $2-3$ & 3 & 73.75 & $3-4$ & $2-3$ & 65.00 & $3-4$ & 3 \\
$\mathrm{D}_{13}$ & 71.25 & 3 & $3-4$ & 74.50 & $4-5$ & 3 & 68.87 & 3 & 4 \\
$\mathrm{D}_{14}$ & 70.00 & 3 & $2-3$ & 73.00 & 4 & $2-3$ & 67.50 & 4 & 4 \\
$\mathrm{D}_{15}$ & 65.00 & $2-3$ & 3 & 70.00 & $2-3$ & 3 & 65.50 & $4-5$ & $2-3$ \\
\hline
\end{tabular}

$\%$ Ex. $=\%$ Exhaustion $;$ L.F. = Light fastness $;$ W.F. = Wash fastness 


\section{Acknowledgement}

The authors are thankful to Principal, Sir P.T.Sarvajanik College of Science, Surat, for providing research facilities and Atul Ltd. Atul for chemicals and dyeing facilities. One of the authors is thankful to Veer Narmad South Gujarat University for providing Research Fellowship.

\section{References}

1. Shah K M, Hand Book of Synthetic Dyes and Pigments, Multi-Tech. Publishing Co., 1994, 1, 184.

2. Abrahat E N, Dyes and their intermediates, Edward Arnold Publishers, London, 1976, 170.

3. Desai J A and Patel V S, Indian J Tex Res., 1985, 10, 72.

4. $\quad$ Patel N C and Mehta A G, Oriental J Chem., 2003, 19(3), 719-720.

5. Fried Bernard and Sherma Joseph, Thin Layer Chromatography Technique and Application, Marcel Decker Inc., NY and Basel, 1982.

6. Shenai V A, Chemistry of Dyes and Principles of Dyeing, Sevak Publication, Mumbai, 1973. 


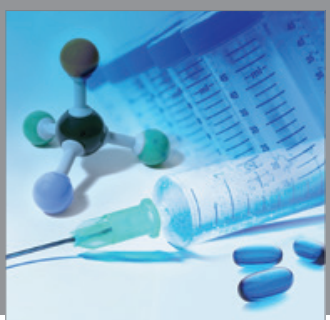

International Journal of

Medicinal Chemistry

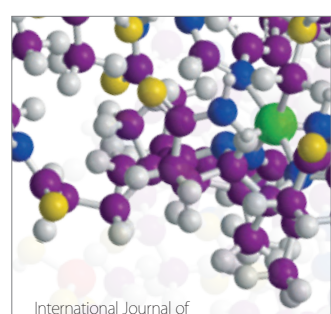

Carbohydrate Chemistry

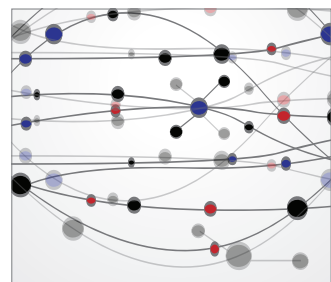

The Scientific World Journal
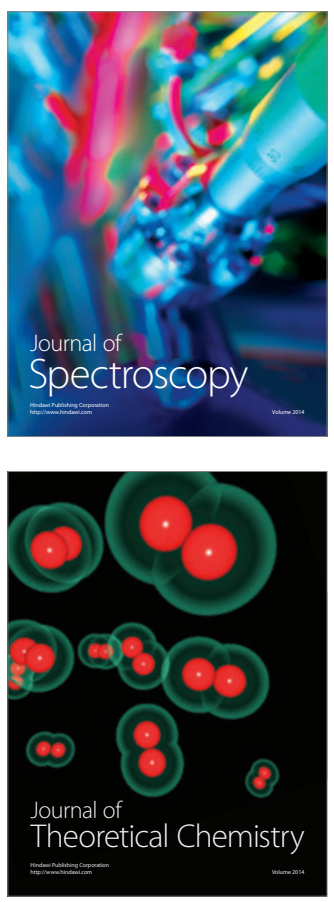
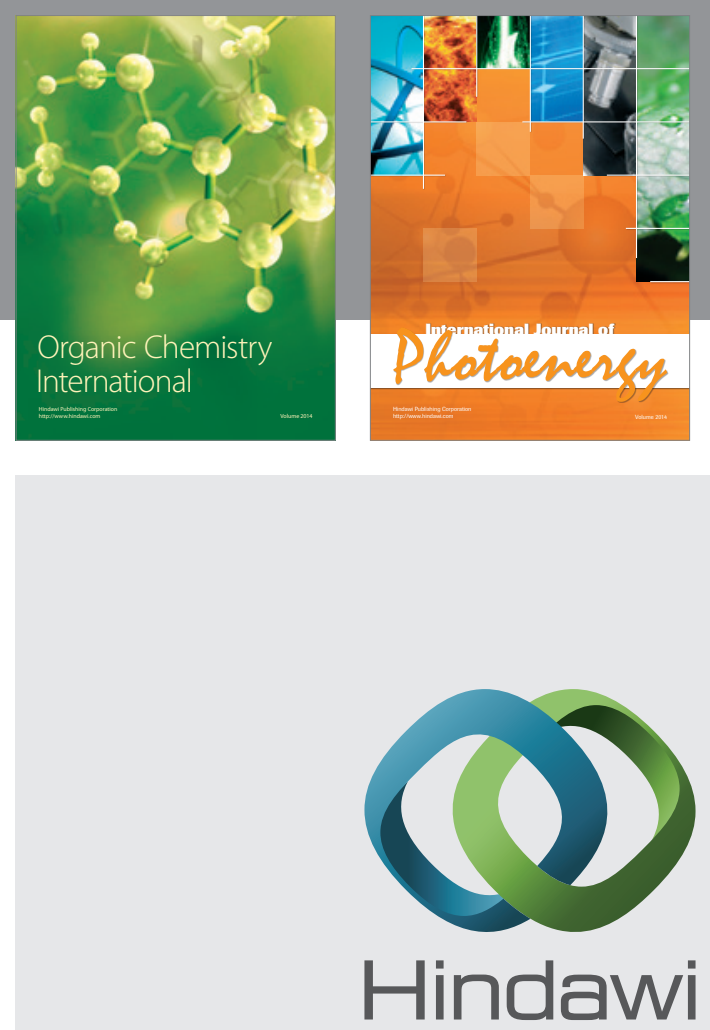

Submit your manuscripts at

http://www.hindawi.com
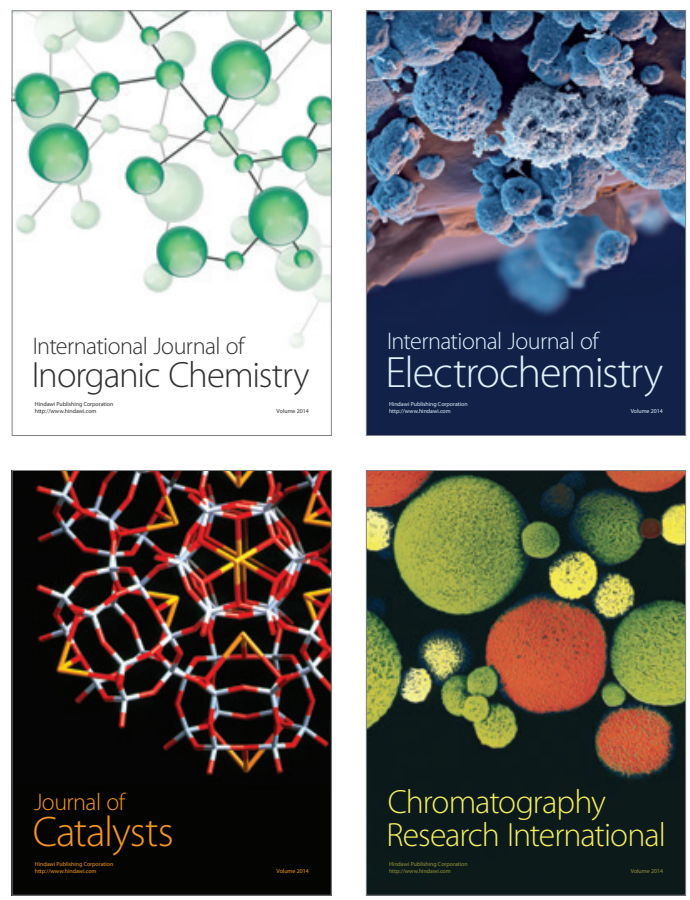
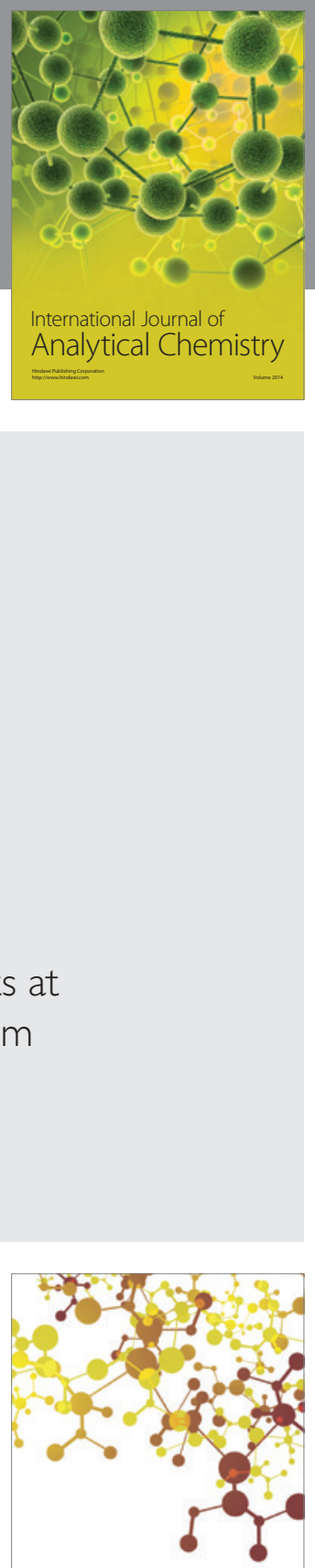

Journal of

Applied Chemistry
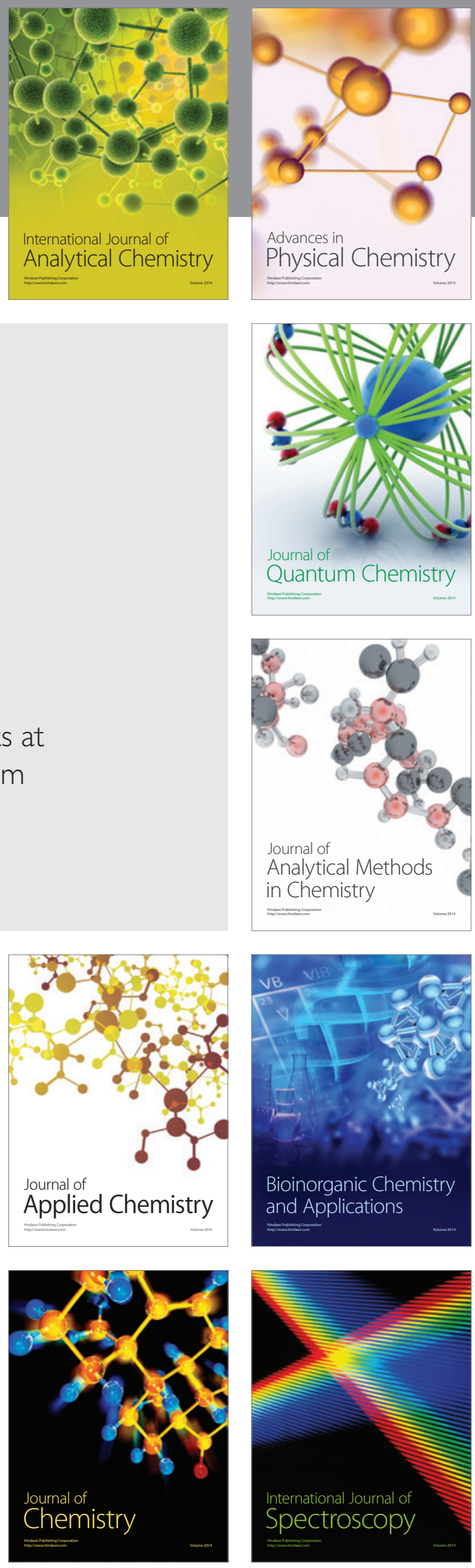